\title{
No relationship between foot posture and frontal knee alignment in healthy adolescents
}

\author{
Shinsuke Matsumoto*, Shigeharu Tanaka \\ From 4th Congress of the International Foot and Ankle Biomechanics (i-FAB) Community \\ Busan, Korea. 8-11 April 2014
}

\section{Background}

Foot posture has been suggested to be related to the development of lower-limb musculoskeletal conditions because of its potential influence on the mechanical alignment and dynamic function of the lower limb. During most weight bearing activities, the posture and motion of the foot and knee are coupled within a closed kinematic chain. The exact relationship, however, between them in healthy individuals is not known. The purpose of this study was therefore to investigate if foot posture was related with frontal knee alignment in healthy adolescents.

\section{Methods}

The foot posture and frontal knee alignment of Fortyeight healthy individuals ( 27 females, average age 21.1 \pm 2.8 yr, BMI $21.0 \pm 1.9$ ) was assessed and then analyzed to determine if any relationship exist between them.

The foot posture measurement was evaluated using FPI [1]. FPI values ranged from -2 to +2 for each of the six criteria and from -12 (highly supinated) to +12 (highly pronated) for the total score. The raw FPI scores were converted to transformed scores to allow the scores to be used as interval data for statistical analysis.

The Knee alignment measure was performed by measuring the femoral tibial angle (FTA) with a goniometer [2]. The axis of the goniometer was positioned over the centre of the patella and the arms were aligned with the midthigh and with the tibial shaft.

Means of the FPI score and FTA were compared by gender using Student's $t$-test. Pearson's correlation coefficient was used to investigate the relationship between the FPI score and FTA.

\section{Results}

There was no difference between FTA of males and females ( 176.5 vs. $176.7 ; \mathrm{p}=0.792$ ). The significant difference in FPI score between males and females was found (5.95 vs. $2.85 ; \mathrm{p}=0.001$ ). No relationship was found between the FPI score and FTA $(r=0.006, p=0.978)$.

\section{Conclusion}

Static foot posture as quantified by FPI and frontal knee alignment as quantified by FTA do not seem to correlate each other in healthy adolescents. These results should be interpreted with caution due to a small sample size.

\section{Published: 8 April 2014}

\section{References}

1. Redmond AC, Crosbie J, Ouvrier RA: Development and validation of a novel rating system for scoring standing foot posture: the Foot Posture Index. Clin Biomech 2006, 21:89-98.

2. Kraus VB, Vail TP, Worrell T, McDaniel G: A comparative assessment of alignment angle of the knee by radiographic and physical examination methods. Arthritis Rheum 2005, 52:1730-5.

\section{doi:10.1186/1757-1146-7-S1-A56}

Cite this article as: Matsumoto and Tanaka: No relationship between foot posture and frontal knee alignment in healthy adolescents. Journal of Foot and Ankle Research 2014 7(Suppl 1):A56.

Submit your next manuscript to BioMed Central and take full advantage of:

- Convenient online submission

- Thorough peer review

- No space constraints or color figure charges

- Immediate publication on acceptance

- Inclusion in PubMed, CAS, Scopus and Google Scholar

- Research which is freely available for redistribution

\footnotetext{
* Correspondence: shinn226@med.kawasaki-m.ac.jp

Dept. of Physical Therapy, Kawasaki Junior College of Rehabilitation, Kurashiki, Okayama, 701-0192, Japan
} 